THE ANNALS OF "DUNAREA DE JOS" UNIVERSITY OF GALATI

FASCICLE XV ISSN - 1454 - 9832 - Vol. 2/2019

Article DOI: https://doi.org/10.35219/efms.2019.2.11

\title{
PLANNING ASPECTS IN TRAINING ICE HOCKEY PLAYERS
}

\author{
PhD Research Assistant Marius TRANDAFIR ${ }^{1}$ \\ PhD Prof. Lorand BALINT ${ }^{2}$ \\ ${ }^{1}$ Dunărea de Jos University of Galați, Str. Domnească, nr. 47, Galați, 800008, România \\ E-mail: marius77trandafir@yahoo.com \\ ${ }^{2}$ Transilvania University of Brașov, Bulevardul Eroilor 29, Brașov, 500036, România
}

\begin{abstract}
Sports training is a long-lasting complex process, organized according to the level of performance and the proposed competitive objective. The study aims at highlighting the planning aspects of the sports training in the preparation of ice hockey players. Training planning is organized according to the team's performance level and the targeted result, thus, it can be classified as follows: stage one, anatomical adaptation, stage two, pre-competition stage, competition stage and the transitional stage. The content of each stage is structured and distributed based on the type of effort specific to the hockey game and the main parameters of effort (volume, intensity, complexity). The research methods used for the elaboration of the study are : the study of specialized literature and the pedagogical observation. Sports training is a pedagogical process, which implies compliance with basic principles that ensure the achievement of the established sporting performance, when the methods and means of training are well chosen, adapted and individualised according to the player's bio-mental-physical abilities and his background on the position in the team.
\end{abstract}

In conclusion, in the course of the sports training process, the physical, physiological, mental and intellectual potential of the sportsman will be improved, through planning and periodization elements, which ensure the achievement of high-level sports performance.

Keywords: sports - hockey - training - performance.

\section{Introduction}

The concept of planning has developed over the years both through contributions from researchers (eg. Ozolin, Harre, Pfeifer, Bompa, Platonov, etc.) as well as through alternative criticism and proposals (eg. distribution in blocks, nonlinear, proposed by Brown), fractal, proposed by Issurin and the conjugate sequence proposed by Siff, Verkhoshansky, Bondarciuk, among other critics Horwill, Zanon, Tschiene, etc.). A series of authors, including Verchoshanskij (1999), Bourne (2008), Koprivica (2012), Platonov (2015), Lyakh, and others (2016) make an exhaustive analysis of the "new" models, highlighting the strengths and weaknesses of each approach. Among the weaknesses deeply affecting the results of the research we mention: the superficial study of Matveyev's theory; the lack of scientific support, the primitive approach of the methodological concept, the theories being proposed without any objective terminological basis; a poor understanding of the features of high performance sports activity; lack of knowledge in related sciences and of findings from the training environment. (Verchoshanskij, 1999; Bourne, 2008; Kiely, 2012; Koprivica, 2012; Platonov, 2015; Lyakh and others, 2016).

With reference to the planning in performance sport, Alexe N. argues that the strategies are projections of a team's journey towards a long-term, medium and short-term goal, transposed into the three types of plans quoted by Alexe: perspective plans, the current plan and the operational plan. (Alexe, 1993, p. 424)

In Matveyev's opinion, sports performance should be conditioned by the development laws of the athlete's preparation status, namely by the sportsman's shape and not by the season and the competition calendar, separating the notion of state created by the training, like the functions of training: physical, technical, tactical, psychological. (Matveyev, 1981)

Naclerio and colleagues (2013) describe the periodization as "methodological planning and structuring of the training process involving a logical and systematic sequencing of multiple training variables (intensity, volume, frequency, period of recovery and exercise) in an integrative manner designed to optimise the results of 
specific performance at predetermined times. (Naclerio and Colleges, 2013) In a short definition, periodization is the systematic planning of sports training. (Rowbottom, 2000, p. 499).

The aim of this study is to highlight the planning aspects of the sports training in the preparation of the ice hockey players. Thus, we aim to bring scientific arguments highlighting the necessity of planning in preparing the ice hockey players, a condition for achieving high-level sporting performance.

\section{Research Methods}

The study of specialized literature and the pedagogical observation were the methods we used in this study.

\section{Results and Discussions} field

Results of the study - opinions of the experts in the

On studying Matveyev's "periodic archetypal model", Kiely (2012) notes that it "was characterized by a progressive transition from high to low volume and from low to high intensity, accompanied by a simultaneous reduction of the variation, as the competitive peak was approached. " (Kiely, 2012) In view of these characteristics, DeWeese and colleagues (2015) have synthesized the main objectives of the period, as follows:

(a) An adequate balance of training loads and competitive training during the season;

(b) Managing fatigue and reducing the overtraining potential;

(c) Appropriate setting and maximum timetable. '

(DeWeese and colleagues, 2015)

The general structure of the periodiziation theory, according to Matveyev and supplemented by Platonov, is the following:

- Megastructure, multi-annual structure and its stages, four-year Olympic cycles, with two stages: the training of the highest sports mastery (7-8 to 10-12 years, divided into: self-reliant preparatory, basic preparatory preliminary, specialised basic training and training for the highest performance) and the development and valorisation of maximum sports mastery (2-3 to 10-15 years, even more, with three stages: maximum valorisation of individual possibilities, maintaining the maximum sporting mastery, gradual decrease of performance);

- Macrostructure, the structure of large cycles (macrocycles) of half-year training types, of one year and several years, comprising annual training cycles, consisting of one or more macrocycles, with three periods: preparatory, competition and participation in the main competitions;
- Mesostructure, a structure of medium cycles (mesocycles), comprising a complete series of microcycles, with precise purposes: adaptation, basic, preparation -regeneration, regeneration -maintenance, special training, precompetitional; competitive;

- Microstructure -a structure of microcycles, training lessons or series of lessons, highlighting microcycles of adaptation, shock, adjustment, regeneration and competitional. (Platonov, 2015, p. 6668; Matveyev, 1981, p. 246)

While Bompa considers that "the main criterion for the duration of each preparation stage is the competition program", (Bompa, 2002, p. 165), Lyakh and colleagues notice that higher sporting performance can be obtained in a holistic and multiannual training process, taking into account the fundamental principles of periodiziation (Lyakh and colleagues, 2016), presented by Platonov a follows:

-Striving for the greatest achievements. The greatest achievements, the purpose of the sports training;

The thorough specialization, largely determined and the purpose of the preparation, given that not only between sports branches there are differences but also between the various competitions in the same branch;

-The unity between the general training (fundamental, basic) and the special preparation, the special training being achieved only by a basis on whose quality it depends;

- The continuous character of the training process, preventing inadequacies;

-Unity between the gradual nature of effort increase and the tendency towards maximal efforts, which ensures the progress of the sports training, through adaptation and overcompensation;

-the wavy and varied character of efforts, for integrating very high efforts and preventing overtraining;

- The cyclicality of the preparation process, taking into account both the training regularities of sports mastery and the relatively stable competitional system;

-Unity and the reciprocal link between the structure of the competition activity and the structure of the preparation, which allows the modeling of the competitive activity as a method of preparation, too;

-The unity and the reciprocal link between the training process and the competitive activity with factors that are exterior to the training framework, the increase of sporting performance according to external factors such as sports equipment, sports infrastructure, etc.;

-the reciprocal link between the training process and prophylaxis of trauma and occupational illnesses, taking into account the reduction or elimination of the identified risk factors. (Platonov, 2015, p. 74-85)

Many coaches and researchers believe that the periodization is a very flexible tool, which, if used together with appropriate training techniques, is an essential component in achieving long-term performance. Instead, according to Nacleiro and colleagues (2013), some team sport coaches propose training plans that break 
the principles of periodization, in order to adapt to the mid-week planned competitive periods. (Naclerio and colleagues, 2013)

Balyi (2011) integrates the periodization in the long-term development model of athletes, the phases of the annual planning through this model being presented in figure No. 1 .

In Canada many of the sport branches have adopted this integrating vision (e.g. hockey, water polo, skiing, basketball, karate, etc.), implementing national programmes from initiation.

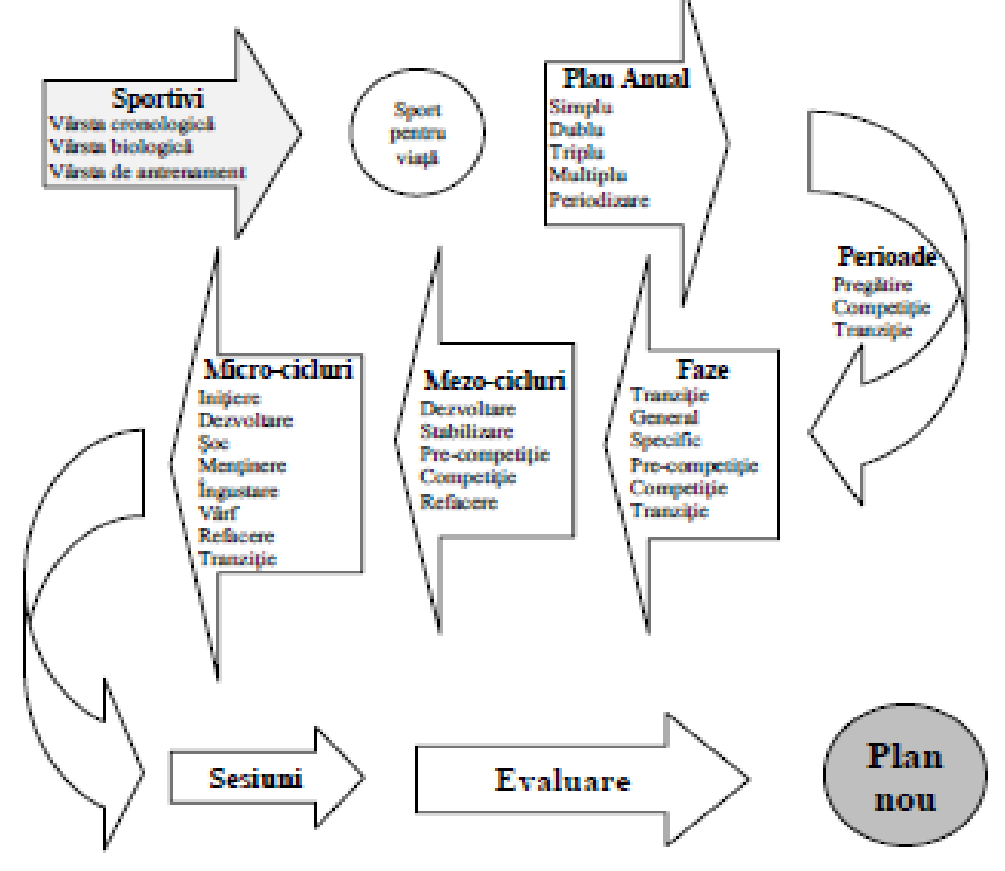

Figure no. 1. Long-term development model of athletes - annual planning phases

Athletes

Chronological age

Biological age

Training age

$\begin{array}{ll}\text { Periods } & \text { Microcycles } \\ \text { Preparation } & \text { Initiation } \\ \text { Competition } & \text { Development } \\ \text { Transition } & \text { Shock } \\ & \text { Maintenance } \\ & \text { Narrowing } \\ & \text { Peak } \\ & \text { Rehabilitation } \\ & \text { Transition }\end{array}$

Sessions

Assessment

The multiannual plan. In general, for Olympic sports and teams aiming to participate in this competition, or for the preparation of juniors and young people, depending on their biological development, but also for other categories of athletes, it is possible to

Annual Plan
Simple
Double
Triple
Multiple
Periodization

Mesocycles

Development

Stabilisation

Transition

Pre-competition

Competition

General

Pre-competition

Competition

Transition

Transition

New Plan

draw up multiannual training plans. Ozolin (1970), quoted by Platonov (2015), showed that "the multiannual preparation for the highest performance must last from 8 to 12 years and should be divided into 
two periods: preparatory and special". (Platonov, 2015, p. 219)

For ice hockey and other sport branches imposing "the art of movement to a significant manifestation of speed, strength and endurance", the age limits are, in the opinion of Ozolin (1970), the following:

- 10-13 years, the preparatory period, "which must ensure multilateral motor development and the creation of morphological, physiological, psychological, technical, etc. for specialised training";

- 14-15 years, the first stage of the special period, in which "emphasis is placed on the improvement of sporting technique, on basic physical training, increase of coordination capacity of complex movements and actions" - 16-17 years, second stage of the special period, oriented towards "a high level of special training, on technical improvement and special psychological training";

- From the age of 18, the third stage of the special period in which the preparation is "oriented towards achieving the highest sporting results, on the basis of a rational periodization of annual training". (Platonov, 2015, p. 219)

The annual plan is the most important document elaborated in the training process, a document whereby both training objectives and factors are established, expressed temporally, quantitatively (volume, intensity) and qualitatively ( efficiency, results).

Olbrecht, quoted by Platonov, recommends the use of five principles for a rational planning of the structural formations of the training process, indicating their influence, reflected in figure No. 2 by the number of arrows.

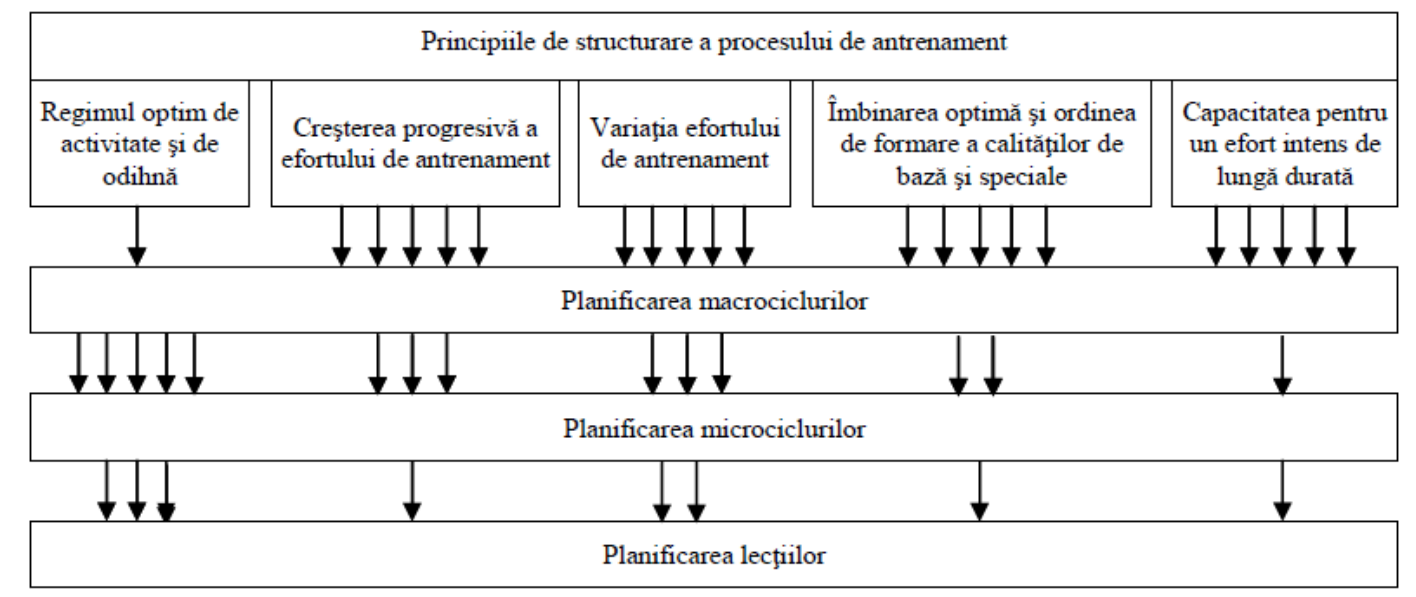

Figure no. 2. Structural formation principles of the trainin process and their contribution in planning the training process (Olbrecht, quoted by Platonov, 2015, p. 481)

Optimum activity and rest conditions

Structural Training Principles

Progressve increase of training effort

Variation of training effort

Optimum combination and training order of basic and special qualities

Capacity for intense effort of long duration

Planning macrocycles

Planning mesocycles

Ploanning lessons

The annual plans can be monocyclic, for athletes who are preparing for a single major competition per year, bicyclic or even multicyclic, depending on the number of major competitions. If there are several competitions foreseen in a training plan, the most important of them are considered to require the peak of the type and are planned in the last cycle. In multi-cyclical planning, the first period of preparation is the longest, period in which "the athlete builds the technical, tactical and physical bases that will support the next two cycles," "the volume curve is the highest" and "intensity curve of each cycle follows 
a pattern resembling a monocycle. " (Bompa, 2001, p. 171)

Platonov (2015) presents three different training strategies, "both in relation to the objectives and to the structure and the training process":

- the first strategy, "is conditioned by the objective of successful participation in the main competitions of the year", the other competitions having a secondary character, participation in these competitions being a method of training and verification of the efficiency of the plan preparation;

- the second strategy reflects a "harmonisation of effective training for different competitions, carried out over a long period of time (up to 8-10 year) months, with the preparation for successful development in the main competitions";

- the third strategy is "characteristic for to branches in which athletes are forced to evolve during the largest part of the year, being oriented towards achieving the highest results". (Platonov, 2015, p. 333-390)

In Romania, the concept of planning penetrated relatively quickly and was easily assimilated into athletes ' training programs. In the volume published in 1962, Flamaropol presented the three phases of the training for hockey teams, valid today:

- preparatory, which aims at restoring physical and special training to the level of the competition period of the preceding season and then raising them to a higher level; development and gradual improvement of basic physical and moral qualities and qualities of the will; restoring, acquiring and perfecting the level of technical and tactical training;

- competition training, in which the training activity has a precise orientation, towards the objectives of the competitions, by: the continuous raising of the training degree to achieve the sport form in the important games; enhancement of the technical-tactical training for games, aiming at the achievement of a fast tempo of gameplay through actions carried out in speed and tactical development for future games; individualisation of players ' training; fixing the game system and practicing different combinations and variants; the development of the players ' moral forces and the strengthening of the team spirit, to increase the combativity, strength and confidence in their own forces; purchase of the best materials;

- the transitional period, lasting 30 days, in which the gradual decline in effort occurs; body restoration after the efforts of active sleep, taking into account the structure of energy consumption and the training of the energy system; enhancing health, treating trauma; the accumulation of new knowledge through the analysis of games from the competition period; maintaining general physical training at an appropriate level. (Flamaropol, 1962, p. 278-282)

Kosta specifies that in the first stage of the preparatory period the amount of effort gradually increases, having 4-5 workouts/week, with varied content, and in the second stage decreasing the volume, but increasing the intensity of the training, having 5-6 workouts/week, maximum 2 hours/workout. (Kosta, 1975 p. 246)

According to Platonov, the periodization of the physical training of sport teams, insufficiently researched, includes a competitive season of about eight to nine months a year, where club teams can have both matches in the national championships and in the international ones, the matches also taking place at intervals of 3-4 days, a special situation being that of the players who are also part of the representative the national teams, whose effort is obviously greater and considerably decreases the period of rest. Platonov recommends that these players be exempted from certain matches, for example those with weaker opponents, so that they can have 10-15 day breaks for intense training programs. (Platonov, 2015, p. 453454) The necessity of collaboration between the coaches of the two teams, the club and the national lot is obvious, for the elaboration of training based on rational bases, the elaboration of individual training plans for these athletes and the use of official matches as a training method in order to achieve the best sporting performance.

Bompa and Chambers (2003) synthesize the objectives of the annual training plan, depending on each phase of the hockey training. Also, Bompa (2002) notes that an athlete also undergoes a cycle of psychological overcompensation, which "begins before the physiological overcompensation, in the first days of the narrowing to the peak of form for competition". (Bompa, 2002, p. 173)

During the preparation phase, the hockey player's, physical, technical, tactical and psychological development is achieved and a very good fatigue resistance, too. In this respect, the hockey player:

1. "Learns about the importance of improving general physical training;

2. Improve the physical factors involved in hockey, such as: strength, speed, power, endurance/aerobic and anaerobic resistance, agility and flexibility;

3. Development and/or improvement of the technique;

4. Determination and knowledge of basic tactics in the following phases. In hockey, this phase lasts 34 months or more. " (Bompa and Chambers, 2003, p. 5).

According to Bompa and Chambers (2003), in the competition phase, $90 \%$ of the training is focused on hockey-specific training, the objective being to get the peak of shape during play-off and players must:

1. "Continue to improve the physical and psychological abilities of hockey." 


\section{THE ANNALS OF "DUNAREA DE JOS" UNIVERSITY OF GALATI \\ FASCICLE XV ISSN - 1454 - 9832 - Vol. 2/2019}

2. Improve and consolidate technical skills.

3. Develop tactics and gain competitive experience.

4. Maintain general physical training. " (Bompa and Chambers, 2003, p. 6)

Bompa and Chambers (2003) believe that a higher performance is achieved, on the principles of periodization, a training plan that will integrate systemically all the training components of the hockey players, physical psychological and nutritional, an integrated pattern of periodization for ice hockey being presented. (Bompa and Chambers, 2003, p. 9)

Mike Cavanaugh (2016), coach of the University of Connecticut hockey team, uses the daily training program as a way to communicate to the team his vision, to determine each player to be part of the team, for the success of the group and not for the glory of the individual.

An important aspect in the whole preparation process is the recovery from intense efforts, by reducing fatigue of the body, by mental relaxation and general replenishment with energy, so that the continuation of the workouts may have deep negative effects, both at the individual level and at the team level. (Bompa, 2000, p. 80)

In applying the concept of periodization and planning, synergy is essential, in the sense that the whole is greater than the sum of the parties, thus the preparation components obtained gaining value only together, in an ensemble, for high performance. (Gambetta, 1989)

\section{Conclusions}

The planning of sport training involves a multidirectional process aimed at influencing the physical, mental, intellectual and physiological influence of the athlete's body in order to achieve the proposed performance objectives.

The coach is one of the important factors of the entire training process, he has multiple roles on team management: educator, mentor, resource manager, catalyst, activator, organizer, spokesperson, etc.

"The coach can be defined as the person who deals with designing and directing the training process for young people, in order to develop their performance capacity and to gain victories in competitions". (Dragnea and colleagues, 2002, p. 213)

The task of the coach is to "prepare and guide the player so that he can know the game well and give good results, according to physical, theoretical and moral training, through specific methods, supported by pedagogical principles, personal example, consistency.

Improving the potential of athletes through the planning process depends on the competence of the coach and by default the training techniques adopted in the preparation process.

In the course of the sport training process, it is intended to exploit the physical, physiological, mental and intellectual potential of the sportsman, through planning and periodization elements, which ensures the achievement of high-level performance.

The management of the hockey team assumes both the organisation and the assurance of the conditions of preparation and the efficient management of the potential of the team from a physical, mental and intellectual point of view.

\section{References}

1. Alexe, Nicu (coordonator) (1993) Antrenamentul sportiv modern, Editura EDITIS, București

2. Balyi, Istvan (2011) Paradigm Shifts in Sport and Coaching, conferinţă susţinută la Standford University

3. Bompa, Tudor O (2002) Periodizarea: teoria și metodologia antrenamentului, Editura Ex Ponto.

4.Bompa, Tudor; Chambers, Dave (2003) Total Hockey Conditioning: From pee-wee to Pro, Firefly Books

5. DeWeese, Brad H.; Hornsby, Guy; Stone, Meg; Stone, Michael H. (2015) The training process: Planning

for strength-power training in track and field. Part 2: Practical and applied aspects, Journal of Sport and Health Science 4 (2015), pag. 318-324

6. Kiely, John (2012) Periodization Paradigms in the 21st Century: Evidence-Led or Tradition-Driven?, în International Journal of Sports Physiology and Performance, 7 , pag. 242-250

7. Kostka, Vladimir (1975) Hochei: jocul modern, Editura Sport-Turism

8. Lyakh, Vladimir; Mikołajec, Kazimierz; Bujas, Przemysław; Witkowski, Zbigniew; Zając, Tomasz; Litkowycz, Ryszard; Banyś, Damian (2016) Periodization in Team Sport Games - A Review of Current Knowledge and Modern Trends in Competitive Sports, în Journal of Human Kinetics, volume 54/2016, pag. 173-180

9. Matveyev, L (1981) Fundamentals of Sports Training, Progress Publisher

10. Naclerio, Fernando; Moody, Jeremy; Chapman, Mark (2013) Applied Periodization: A Methodological Approach, în Journal of Human Sport \& Exercise, Volume 8, Issue 2, pag. 350- 366

11. Platonov, Vladimir Nikolaevici (2015) Periodizarea antrenamentului sportiv: teoria generală şi aplicaţiile ei practice, Editura Discobolul.

12. Rowbottom, David J. (2000) Periodization of Training, in Garrett, William E.; Kirkendall, Donald T. (editori) (2000) Exercise and Sport Science, Lippincott Williams \& Wilkins 